\title{
K167 and DLX2 predict increased risk of metastasis formation in prostate cancer-a targeted molecular approach
}

William JF Green ${ }^{1}$, Graham Ball ${ }^{2}$, Geoffrey Hulman ${ }^{3}$, Catherine Johnson ${ }^{2}$, Gerry Van Schalwyk ${ }^{4}$, Hari L Ratan ${ }^{1}$, Daniel Soria ${ }^{5}$, Jonathan M Garibaldi ${ }^{5}$, Richard Parkinson ${ }^{1}$, Joshua Hulman ${ }^{3}$, Robert Rees ${ }^{2}$ and Desmond G Powe ${ }^{\star, 2,3}$

\begin{abstract}
${ }^{1}$ Department of Urology, Queen's Medical Centre, Nottingham University Hospitals NHS Trust, Nottingham NG7 2UH, UK; ${ }^{2} T$ The John van Geest Cancer Research Centre, Department of Life Sciences, Nottingham Trent University, Nottingham NG11 8NS, UK; ${ }^{3}$ Department of Cellular Pathology, Nottingham University Hospitals NHS Trust, Nottingham NG7 2UH, UK; ${ }^{4}$ Pathology Department, Division of Planned Care, Royal Derby Hospital, Derby DE22 3NE, UK and ${ }^{5}$ Advanced Data Analysis Centre, School of Computer Science, Faculty of Science, University of Nottingham, Nottingham NG8 1BB, UK
\end{abstract}

Background: There remains a need to identify and validate biomarkers for predicting prostate cancer (CaP) outcomes using robust and routinely available pathology techniques to identify men at most risk of premature death due to prostate cancer. Previous immunohistochemical studies suggest the proliferation marker Ki67 might be a predictor of survival, independently of PSA and Gleason score. We performed a validation study of Ki67 as a marker of survival and disease progression and compared its performance against another candidate biomarker, DLX2, selected using artificial neural network analysis.

Methods: A tissue microarray (TMA) was constructed from transurethral resected prostatectomy histology samples $(n=192)$. Artificial neural network analysis was used to identify candidate markers conferring increased risk of death and metastasis in a public cDNA array. Immunohistochemical analysis of the TMA was carried out and univariate and multivariate tests performed to explore the association of tumour protein levels of Ki67 and DLX2 with time to death and metastasis.

Results: Univariate analysis demonstrated Ki67 as predictive of CaP-specific survival (DSS; $P=0.022)$, and both Ki67 $(P=0.025)$ and DLX2 $(P=0.001)$ as predictive of future metastases. Multivariate analysis demonstrated Ki67 as independent of PSA, Gleason score and D'Amico risk category for DSS (HR=2.436, $P=0.029)$ and both $K i 67(H R=3.296, P=0.023)$ and DLX2 $(H R=3.051, P=0.003)$ as independent for future metastases.

Conclusions: High Ki67 expression is only present in 6.8\% of CaP patients and is predictive of reduced survival and increased risk of metastasis, independent of PSA, Gleason score and D'Amico risk category. DLX2 is a novel marker of increased metastasis risk found in 73\% patients and $8.2 \%$ showed co-expression with a high Ki67 score. Two cancer cell proliferation markers, Ki67 and DLX2, may be able to inform clinical decision-making when identifying patients for active surveillance.

The last decade has seen the development and refinement of predictive risk stratification models in the management of prostate cancer $(\mathrm{CaP})$ (Parekh et al, 2006). These tools are validated for clinical decisionmaking and facilitating informed patient consent to treatment.
These tools aim to apply an objective, evidence-based algorithm to a set of disease parameters, thus moving away from subjective judgments based on clinical experience. Unsurprisingly given the genetic and molecular heterogeneity between

*Correspondence: Dr DG Powe; E-mail: des.powe@nottingham.ac.uk

Received 31 December 2015; revised 29 March 2016; accepted 3 May 2016; published online 23 June 2016

(c) 2016 Cancer Research UK. All rights reserved 0007-0920/16 
individuals, these tools are far from perfect. They cannot always determine an individual's likelihood of clinically significant disease, particularly in classically low to intermediate risk groups, and in those patients undergoing active surveillance (AS) (Wang et al, 2013; Loeb et al, 2014). Increased understanding of the molecular biology of $\mathrm{CaP}$ has identified some biomarkers that are predictive of disease outcome and therapeutic response to treatment (Ben-Porath et al, 2008), for complementary use with the serum PSA test and histological Gleason score assessment.

The TransAtlantic Prostate Cancer Group developed a 31 gene cell-cycle progression (CCP) signature for predicting outcome in CaP (Cuzick et al, 2011, 2012) using conservatively treated transurethral resected prostate (TURP) samples, and validated CCP in radical prostatectomy and initial needle core biopsy (Cuzick et al, 2012). Another predictive test is the commercially available multigene RT-PCR Oncotype DX Prostate Cancer Assay (Genomic Health, Redwood City, CA, USA). A 17-gene panel assesses markers of 4 distinct biological targets: the androgen pathway (AZGP1, KLK2, SRD5A2 and FAM13C), cellular organisation (FLNC, GSN, TPM2 and GSTM2), proliferation (TPX2) and stromal response (BGN, COL1A1 and SFRP4), to produce a 'genomic prostate score' that predicts the likelihood of high-grade/stage disease at diagnosis (Knezevic et al, 2013; Klein et al, 2014).

Cancer cell proliferation is a surrogate of tumour growth and is associated with worsened prognosis in $\mathrm{CaP}$ and other cancer types (Ramsay et al, 2011; Nagalla et al, 2013). Unsurprisingly, measuring the proportion of cancer cells undergoing cell proliferation using the immunohistochemical proliferation marker Ki67 has shown promise as a biomarker for predicting biochemical recurrence in patients with localised CaP (Berney et al, 2009). In addition, Ki67 has been reported to predict distant metastasis formation in intermediate $\mathrm{CaP}$, following radiation therapy (Verhoven et $a l, 2013$ ) and in conjunction with other markers post docetaxel chemotherapy (Antonarakis et al, 2012). It has also demonstrated predictive value in assessing overall survival (OS) and disease-specific survival (DSS) (Fisher et al, 2013). However, there is a lack of consensus when assigning thresholds for dichotomously categorising patients, which have varied from 2.4 to $26 \%$ for biochemical recurrence and from 3 to $10.3 \%$ for DSS.

There remains an unmet need to identify markers capable of reliably assessing an individuals' risk of developing metastasis and castrate resistance. These are important end points for clinical assessment because they are associated with worsening prognosis. In this study, we attempt to validate recent work carried out by Fisher et al (2013) in which they used a single biomarker, Ki67, to predict outcome in a conservatively managed group of patients diagnosed on needle core biopsy. They demonstrated that Ki67 has significant ability to predict $\mathrm{CaP}$-specific death on both univariate and multivariate analysis (compared with PSA and Gleason score). Ki67 has previously been demonstrated to predict survival and recurrence in patients undergoing radical treatment (Pollack et al, 2004; Khor et al, 2009; Zellweger et al, 2009). However, Fisher's work was the first study to demonstrate its prognostic utility from diagnostic biopsy in conservatively managed patients. This is important as this prognostic information could be used as an adjunct in clinical decision-making to reduce the number of patients requiring radical treatment, with all its attendant risks.

However, Fisher's group did not report whether Ki67 is predictive of metastasis. We therefore decided to examine the relationship between Ki67 expression and subsequent metastases and also applied a bioinformatic learning tool, artificial neural network (ANN) analysis, to identify further biomarkers of metastasis development and DSS in a contemporary gene array library of an unselected population of $\mathrm{CaP}$ patients.

\section{MATERIALS AND METHODS}

Patient selection and clinical data collection. About 365 Patients diagnosed with $\mathrm{CaP}$ between 1999 and 2001 were identified. These were consecutive non-selected patients and all underwent 'bestpractice' treatment at Nottingham City Hospital, UK. Initial histological cancer diagnosis was made using tissue obtained by prostate needle core biopsy or TURP specimens. A total of 192 patients were selected for inclusion in the study; 155 patients were excluded to improve cohort homogeneity. Exclusion criteria included patients not undergoing TURP (29), patients lost to follow-up or key parameters not recorded (114). Gleason scoring was modified in 2005 by the International Society of Urological Pathology (ISUP) consensus (Epstein et al, 2005), and for this reason all cases were histologically reviewed and Gleason scored using contemporary ISUP guidelines. Multiple clinicopathological variables were recorded for each patient including PSA and histological Gleason score at diagnosis, time taken to metastasis formation and time taken to CaP-specific death post-diagnosis. Patient management was based on PSA levels, histology Gleason score and clinical staging. Patients were clinically followed-up at 3-6 monthly intervals and the majority of patients received 'watchful waiting'. Androgen deprivation therapy was given for disease progression, indicated by a rapid rise in PSA level, symptoms or metastasis development. Palliative radiotherapy or chemotherapy was administered for symptom control (bone pain or prostate bleeding) in patients with late-stage cancer.

Use of the tissue samples for this study was approved by the North West 7 Research Ethics Committee-Greater Manchester Central REC number 10/H1008/72.

TMA construction. A tissue microarray (TMA) was constructed using archival wax-embedded TURP tissue samples sourced via the Nottingham Health Science BioBank. Histology sections were reviewed by a pathologist $(\mathrm{GH})$ and $0.6 \mathrm{~mm}$ diameter donor cores were sampled from at least two different tumour regions per patient using an automated TMA Grand Master instrument (3DHistech, Budapest, Hungary).

Biomarker selection. Artificial neural network techniques were applied to a publically available $\mathrm{CaP}$ cDNA gene expression array (Wang et al, 2010) to identify biomarkers for predicting tumour metastasis (Powe et al, 2014) so that their performance could be compared with the proliferation marker Ki67. We have previously reported on the use of an ANN technique to identify predictors of metastasis (Powe et al, 2014). Here the ANN model was reiterated 50 times with random sampling and the average mean square error of a test subset for each input variable was considered to determine the predictive capability for metastasis class.

The top 10 genes ranked for association with metastasis development are included in Table 1. Four of these had commercially available antibodies (AMACR (Racemase), DLX2, PAICS and MYO6). DLX2 was selected for validation due to its novelty as a candidate marker in $\mathrm{CaP}$, its putative oncogenic function (Cantile et al, 2005; Morini et al, 2010) and its high ANN ranking. For comparison, a curated literature search was performed to identify evidence for the application of Ki67 as a marker of outcome in CaP (Berney et al, 2009; Antonarakis et al, 2012; Fisher et al, 2013; Verhoven et al, 2013).

Immunohistochemistry. Optimal antibody dilutions and antigen retrieval conditions were performed using positive and negative control tissues suggested by the antibody suppliers. After microwave antigen retrieval in $10 \mathrm{~mm}$ sodium citrate, slides were 
Table 1. ANN ranked gene list showing association with prostate cancer metastasis

\begin{tabular}{|c|c|c|c|}
\hline Rank & Gene accession number & Gene name & Gene product (protein) \\
\hline 1 & AK022765.1 & AMACR & Alpha-methylacyl-CoA racemase \\
\hline 2 & Al796120 & $A M A C R$ & Alpha-methylacyl-CoA racemase \\
\hline 3 & AF047020.1 & AMACR & Alpha-methylacyl-CoA racemase \\
\hline 4 & NM_004405.2 & $D L X 2$ & Distal-less homeobox 2 \\
\hline 5 & & PCA3 & Prostate cancer antigen 3 \\
\hline 6 & NM_012485.1 & HMMR & Hyaluronan-mediated motility receptor (RHAMM or CD168) \\
\hline 7 & U90236.2 & MYO6 & Myosin VI \\
\hline 8 & NM_017636.1 & FLJ20041 & $\begin{array}{l}\text { Hypothetical protein FLJ20041 } \\
\text { Alias: TRPM4B }\end{array}$ \\
\hline 9 & BF511718 & $\mathrm{RHO7}$ & $\begin{array}{l}\text { GTP-binding protein Rho7 } \\
\text { Alias: RND2 }\end{array}$ \\
\hline 10 & NM_006452.1 & $\mathrm{ADE} 2 \mathrm{H} 1$ & $\begin{array}{l}\text { Multifunctional polypeptide similar to SAICAR synthetase and AIR carboxylase } \\
\text { Alias: PAICS }\end{array}$ \\
\hline 11 & NM_002570.1 & PACE4 & Paired basic amino acid cleaving system \\
\hline 12 & NM_004503.1 & HOXC6 & Homeobox C6 \\
\hline
\end{tabular}

Table 2. The number of patients within the prostate cancer cohort that were dichotomously categorised for each biomarker

\begin{tabular}{|l|c|c|c|}
\hline $\begin{array}{l}\text { Biomarker } \\
\text { (score) }\end{array}$ & $\begin{array}{c}\text { Number of cancer } \\
\text { patients scored }\end{array}$ & $\begin{array}{c}\text { Number } \\
\text { positive (\%) }\end{array}$ & $\begin{array}{c}\text { Number } \\
\text { negative (\%) }\end{array}$ \\
\hline Ki67 $(>110)$ & 161 & $11(6.8)$ & $150(93.2)$ \\
\hline $\mathrm{DLX} 2(>10)$ & 185 & $135(73)$ & $50(27)$ \\
\hline
\end{tabular}

sequentially incubated in the primary antibody, detection reagents (Leica Microsystems (UK) Ltd., Milton Keynes, UK) and haematoxylin.

Immunostained TMA sections were assessed to determine the appropriate scoring technique for quantifying protein expression levels. Sections were independently scored (WJFG, DGP) without knowledge of pathology grade. Ki67 and DLX2 nuclear staining was microscopically assessed at $\times 20$ in tumour cells present in the TMA core, using a Histochemical score technique (H-score (McCarty et al, 1985)). The H-score is achieved by summing the product of percentage cells showing each level of staining intensity where $0=$ absence of staining, $1=$ weak staining, $2=$ moderate staining and $3=$ strong staining intensity. Staining thresholds used for dichotomous categorisation were chosen using the software program X-tile (Camp et al, 2004), or by those given in previously published studies. Patients were dichotomously categorised according to the nuclear $\mathrm{H}$-score: positive expression was defined as a score $\geqslant 110$ for Ki67 and $\geqslant 10$ for DLX2.

We used REMARK guidelines (McShane et al, 2006) for reporting on prognostic biomarkers in the whole patient series. The proportion of patients with scorable tissue sections was less than the total number of patients originally incorporated in the TMA due to detachment of cores during processing and because not every section taken from every core contained cancer tissue (independently reviewed by GH). Missing data was assessed for randomness using Little's test (Little, 1986) and Wilcoxon-MannWhitney test, both at $95 \%$ confidence level. We failed to reject the null hypothesis of data being missing completely at random $(P>0.05)$. The proportion of patients with tissue sections suitable for scoring is shown in Table 2.

Statistical analysis. Statistical analysis was performed using SPSS (Version 21; IBM, Portsmouth, Hampshire, UK) applied to verified cancer samples. Pearson's $\chi^{2}$-tests were performed to assess biomarker associations with clinicopathological variables including initial PSA and Gleason score. Kaplan-Meier plots with log-rank tests were used to model biomarker associations with DSS (months) and time (months) to metastasis development from diagnosis. Biomarkers also underwent multivariate Cox proportional hazards regression modelling to assess the additional prognostic value to the initial PSA at diagnosis, Gleason score and initial D'Amico risk category. The significance level used was $P<0.05$. If during biomarker analysis a particular clinicopathological variable was missing (e.g., if it had never been recorded in the notes) then that patient would be excluded from the statistical calculation.

\section{RESULTS}

Patient characteristics are shown in Table 3. Examples of nuclear Ki67 and DLX2 staining are shown in Figure 1.

Ki67. A total 161 out of $192(83.9 \%)$ patients samples had scorable tissue with $11(6.8 \%)$ and 150 (93.2\%) showing positive and negative staining, respectively. Increased nuclear Ki67 expression showed a negative association with OS $\left(\chi^{2}=9.493\right.$, $P=0.002)$ and DSS $\left(\chi^{2}=5.222, P=0.022\right.$; Figure $\left.2 \mathrm{~A}\right)$ and $\mathrm{a}$ positive association with metastatic disease $\left(\chi^{2}=5.058, P=0.025\right.$; Figure 2B). Subsequent multivariate Cox regression analysis demonstrated that Ki67 contributed additional predictive ability to PSA concentration, Gleason score and initial D'Amico risk for DSS (HR $=2.436, P=0.029,95 \% \mathrm{CI}=1.096-5.416)$ and metastasis risk $(\mathrm{HR}=3.296, P=0.023,95 \% \mathrm{CI}=1.1814-9.196)$ (Table 4$)$. All Ki67-positive patients had high-grade cancer (Gleason score 8-10, Groups 4-5), and in addition 8 out of 11 (72.7\%) Ki67-positive patients showed co-expression with DLX2.

DLX2. A total 185 out of 192 patients samples had scorable tissue with $135(73 \%)$ and $50(27 \%)$ showing positive and negative staining, respectively. DLX2 expression was not associated with Gleason score or PSA levels. DLX2 alone was not found to be predictive of DSS $\left(\chi^{2}=2.282, P=0.131\right.$ ) (Figure $2 \mathrm{C}$ ) but increased nuclear DLX2 expression showed a positive association with metastasis development $\left(\chi^{2}=10.207, P=0.001\right.$; Figure $\left.2 \mathrm{D}\right)$, independent of PSA concentration, Gleason score and initial D'Amico risk using multivariate Cox regression analysis $(\mathrm{HR}=2.754$, $P=0.003$, 95\% CI $=1.423-5.332$ ) (Table 4). Co-expression with high Ki67 staining was seen in $8.2 \%$ DLX2-positive tumours. 
Table 3. Characteristics of prostate cancer patients incorporated in the TMA

\begin{tabular}{|c|c|c|c|c|}
\hline Clinical variable & $\begin{array}{l}\text { Number of } \\
\text { patients (\%) }\end{array}$ & Chemotherapy & $\begin{array}{l}\text { Androgen depletion therapy } \\
\text { including orchidectomy (\% All patients) }\end{array}$ & $\begin{array}{l}\text { Radiotherapy } \\
\text { (\% All patients) }\end{array}$ \\
\hline \multicolumn{5}{|l|}{ PSA (ng ml-1) at diagnosis } \\
\hline $\begin{array}{l}\leqslant 4 \\
>4 \\
\text { Not recorded }\end{array}$ & $\begin{aligned} 18 & (9.4) \\
168 & (87.5) \\
6 & (3.125)\end{aligned}$ & & & \\
\hline \multicolumn{5}{|l|}{ Gleason score } \\
\hline $\begin{array}{l}\text { Group 1: } \leqslant 6 \\
\text { Group 2: } 3+4 \\
\text { Group 3: } 4+3 \\
\text { Group 4: } 8 \\
\text { Group 5: } 9-10\end{array}$ & $\begin{array}{c}7(3.6) \\
22(11.5) \\
31(16.1) \\
42(21.9) \\
90(46.9)\end{array}$ & $\begin{aligned} & (0.52) \\
5 & (2.6) \\
5 & (2.6) \\
9 & (4.7) \\
43 & (22.4)\end{aligned}$ & $\begin{aligned} & 6(3.1) \\
4 & (2) \\
6 & (3.1) \\
8 & (4.1) \\
30 & (15.6)\end{aligned}$ & $\begin{array}{c}0 \\
0 \\
2(1) \\
0 \\
3(1.5)\end{array}$ \\
\hline \multicolumn{5}{|l|}{ Metastasis } \\
\hline $\begin{array}{l}\text { At diagnosis } \\
\text { Subsequent metastasis } \\
\text { Never developed metastasis }\end{array}$ & $\begin{array}{l}32(16.6) \\
73(38) \\
87(45.3)\end{array}$ & & & \\
\hline
\end{tabular}
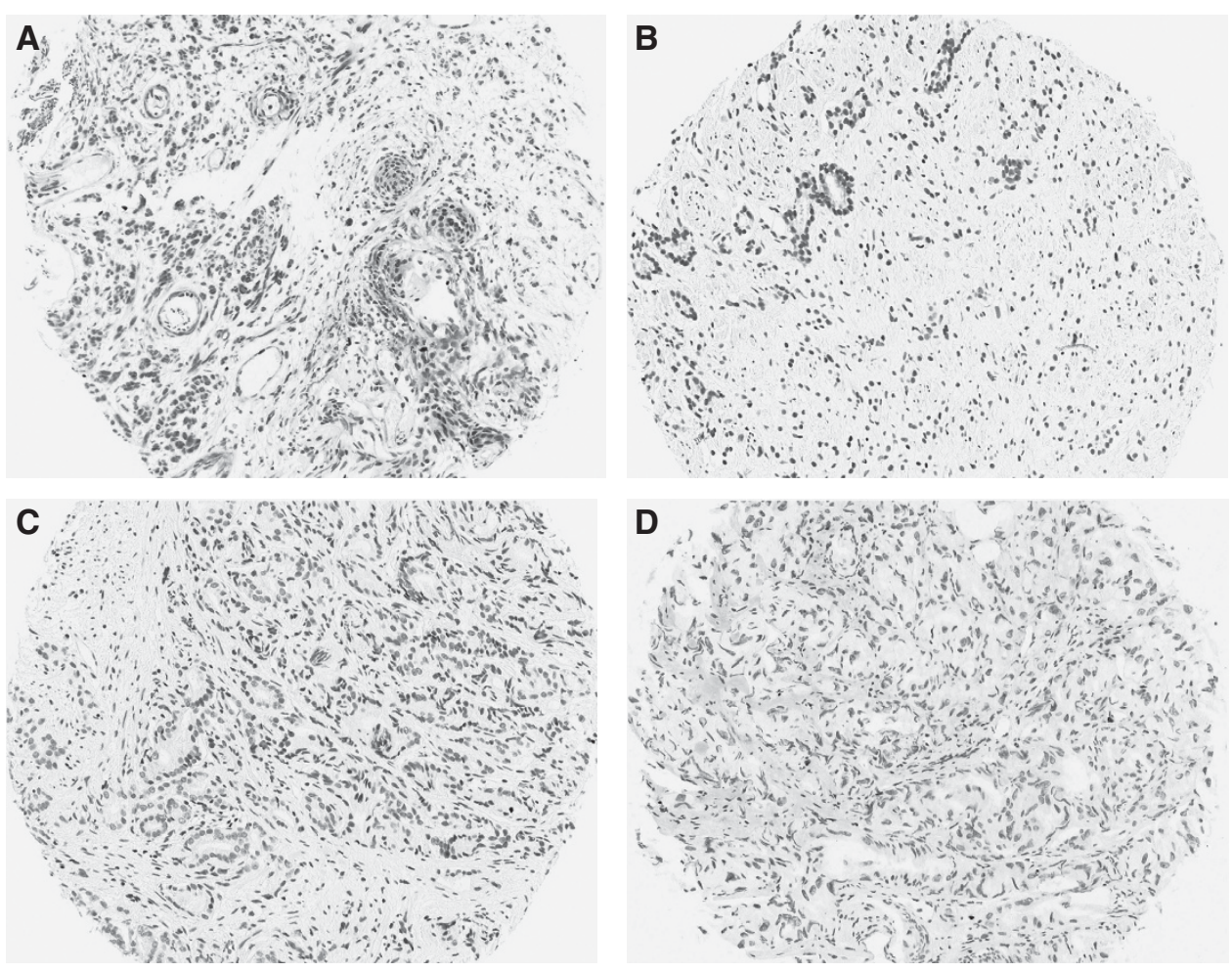

Figure 1. Ki67 and DLX2 localisation in prostate cancer. Examples of positive Ki67 (A) and DLX2 (B) nuclear prostate cancer staining compared with tumours that did not express Ki67 (C) or DLX2 (D).

\section{DISCUSSION}

This study compares the utility of two biomarkers to predict $\mathrm{CaP}$ survival and risk of metastasis in an unselected cohort of $\mathrm{CaP}$ patients with at least 10 years of clinical follow-up. Biomarker selection was based on recent studies highlighting Ki67 as a marker of cell proliferation and outcome in CaP (Pollack et al, 2004;
Berney et al, 2009; Khor et al, 2009; Zellweger et al, 2009; Antonarakis et al, 2012; Verhoven et al, 2013) and a bioinformatic ANN approach applied to a gene expression array derived from $\mathrm{CaP}$ patients, interrogated for markers of metastases. Development of metastasis was associated with increased expression of the tumour markers Ki67 and DLX2. To the best of our knowledge this is the first study of DLX2 being used as a marker of disease progression in CaP. Interestingly, co-expression of Ki67 and DLX2 
A

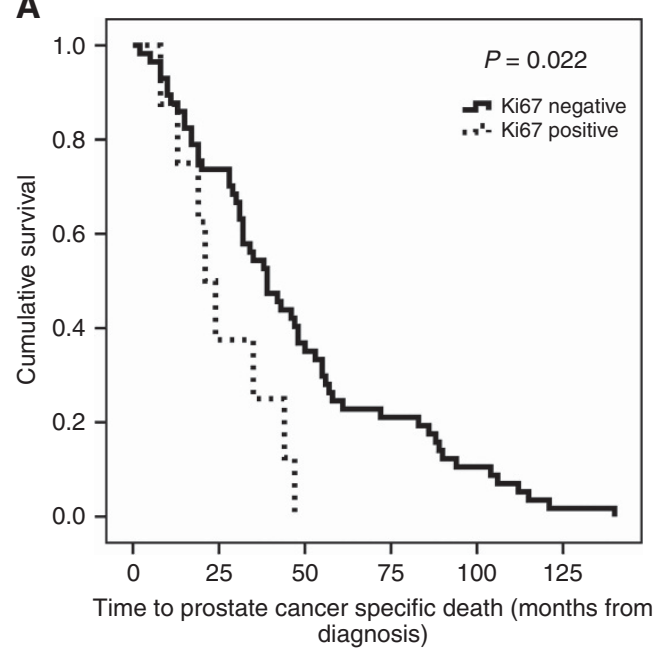

C

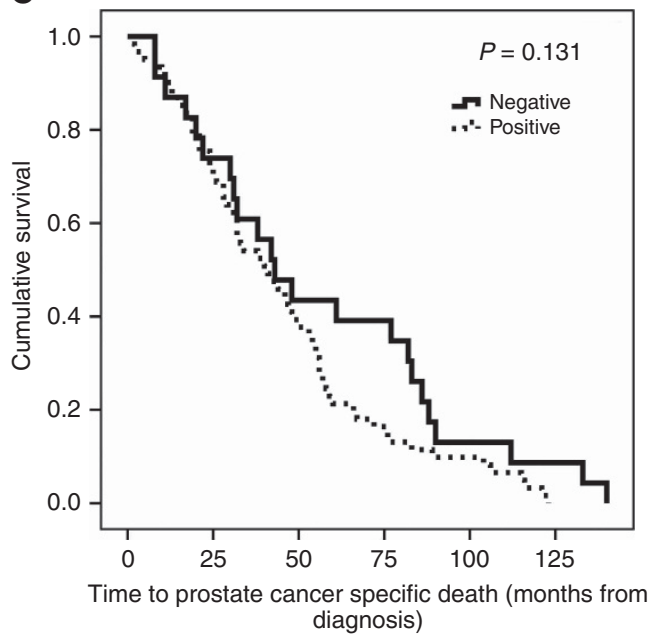

B

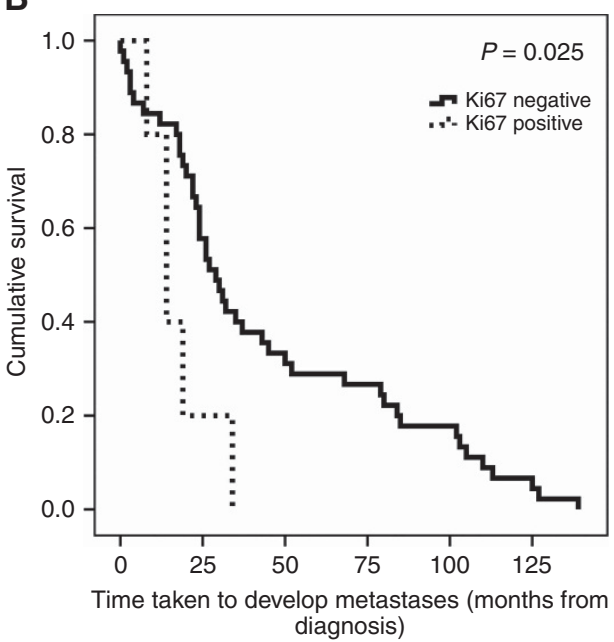

D

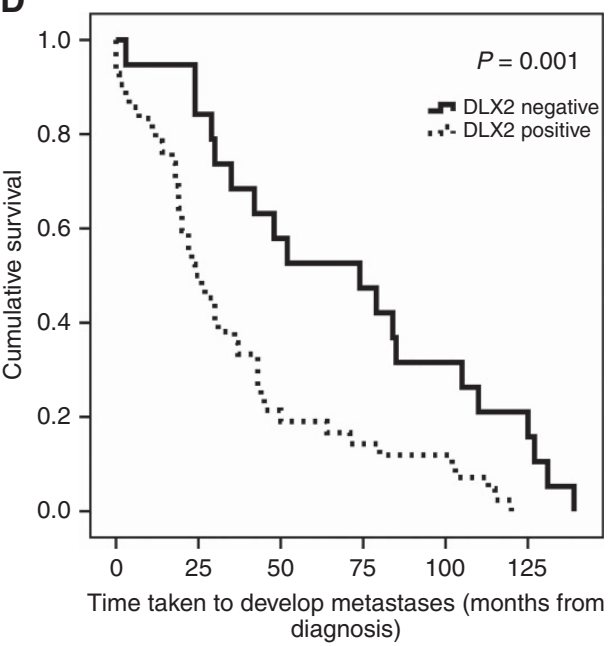

Figure 2. Ki67 and DLX2 are predictive biomarkers of disease progression risk in prostate cancer. Kaplan-Meier plots demonstrating (A) prostate-specific cancer death over time according to Ki67 score. (B) metastasis development over time according to Ki67 score. (C) prostatespecific cancer death over time according to DLX2 score. (D) metastasis development over time according to DLX2 score.

Table 4. Multivariate analysis was performed to assess the predictiveness of Ki67 and DLX2 compared with PSA concentration, Gleason groups and D'Amico risk

\begin{tabular}{|c|c|c|c|c|}
\hline \multirow[b]{2}{*}{ Variable } & \multirow[b]{2}{*}{ Significance } & \multirow[b]{2}{*}{ Hazard ratio } & \multicolumn{2}{|c|}{$\begin{array}{c}95 \% \text { Confidence } \\
\text { interval }\end{array}$} \\
\hline & & & Lower & Upper \\
\hline \multicolumn{5}{|c|}{ Ki67 survival prediction } \\
\hline Ki67 & 0.029 & 2.436 & 1.096 & 5.416 \\
\hline PSA concentration & 0.290 & 1.00 & 1.000 & 1.000 \\
\hline Gleason categories & 0.936 & 1.018 & 0.659 & 1.572 \\
\hline D'Amico risk & 0.964 & 0.919 & 0.347 & 2.433 \\
\hline \multicolumn{5}{|c|}{ Ki67 metastasis prediction } \\
\hline Ki67 & 0.023 & 3.296 & 1.181 & 9.196 \\
\hline PSA concentration & 0.131 & 1.001 & 1.000 & 1.002 \\
\hline Gleason categories & 0.146 & 1.469 & 0.874 & 2.469 \\
\hline D'Amico risk & 0.325 & 0.600 & 0.217 & 1.660 \\
\hline \multicolumn{5}{|c|}{ DLX2 metastasis prediction } \\
\hline DLX2 & 0.003 & 3.051 & 1.451 & 6.418 \\
\hline PSA concentration & 0.202 & 1.002 & 0.999 & 1.004 \\
\hline Gleason categories & 0.768 & 1.081 & 0.643 & 1.819 \\
\hline D'Amico risk & 0.827 & 0.891 & 0.316 & 2.511 \\
\hline
\end{tabular}

occurred in $6.8 \%$ (11 out of 161) scorable patients and was characterised by high cancer grade (Gleason 8-10) and high risk of metastasis.

Ki67 is functionally associated with cellular proliferation and is a surrogate for the growth fraction of tumours. It has been reported to be predictive of CaP-specific mortality (Zellweger et al, 2009; Antonarakis et al, 2012; Verhoven et al, 2013) and we confirm that Ki67 provides prognostic information on disease-specific and OS in $\mathrm{CaP}$. Furthermore, we demonstrated that Ki67 provides additional prognostic utility (HR: 2.19) to the PSA and Gleason score, validating the study by Fisher et al (2013) who recently reported that Ki67 from biopsy tissue independently predicts survival in CaP (HR: 2.78).

In addition to validating Fisher's work (Fisher et al, 2013), we also demonstrated that Ki67 expression is predictive of future metastases in $\mathrm{CaP}$, adding to the small but growing cohort of potential markers of metastasis in this disease. For example, recent work by Columbel et al (2012) has examined the expression of three putative stem cell markers (integrin alpha 2 and 6 and CMET) in men with high-risk $\mathrm{CaP}$. They concluded that the proportion of stem cell-like cancer cells is predictive of bone metastases.

Interestingly only $6.8 \%$ (11 patients) of our cancer cohort had a significantly raised Ki67 and we propose that such patients could be counselled regarding an increased risk of death and metastasis, 
particularly if they are also positive for DLX2, and should be considered for an AS programme. Both markers are known to be functionally important in cancer cell proliferation and, coupled with their association with high Gleason grade reported here, these findings fit with a hypothesis that tumour proliferation rates are a surrogate for tumour aggression and poor prognosis.

Using an ANN approach DLX2 was identified as a marker for metastasis prediction. DLX gene family is involved in embryonic development, tissue homoeostasis, cell cycle and apoptosis (Tang et al, 2013). A growing number of homeobox genes have been shown to be deregulated in a variety of human tumours, and their deregulation is known to enhance cell survival and proliferation and prevent differentiation (Lee et al, 2011). Aberration is reported in breast, lung, ovarian and colon tumours (Morini et al, 2010), and early work has shown that these genes may be involved in neuroendocrine differentiation seen in advanced CaPs (Cantile et al, 2005) but no association with clinical outcomes has ever been reported.

DLX2 has been reported to be involved in shifting TGF $\beta$ from a tumour suppressor to a tumour-promoting function by repressing TGF $\beta$ RII and the cell-cycle inhibitor p21CIP1, and simultaneously increasing the mitogenic transcription factors c-Myc and epidermal growth factor (Yilmaz et al, 2011). In addition, it has been suggested that DLX2 activity may suppress TGF- $\beta$-mediated cell adhesion and migration inhibition (Massagué, 2008). Our novel DLX2 findings validate the ANN bioinformatics approach in revealing it to be a strong predictor of increased metastasis risk (HR: 3.311), more so than either the PSA or Gleason score. DLX2 therefore warrants further investigation because of its ability to assess cancer cell-survival potential.

In summary, we demonstrate that two cell proliferation markers, Ki67 and DLX2, appear to predict CaP-specific survival and metastasis. Independent validation of these findings is needed to establish if Ki67 and DLX2 (especially co-expression) should be considered for prospective clinical trials.

\section{ACKNOWLEDGEMENTS}

We thank Christopher Nolan for his assistance and the Nottingham Hospitals Charity (Special Trustees) for their financial assistance.

\section{CONFLICT OF INTEREST}

The authors declare no conflict of interest.

\section{REFERENCES}

Antonarakis ES, Keizman D, Zhang Z, Gurel B, Lotan TL, Hicks JL, Fedor HL, Carducci MA, De Marzo AM, Eisenberger MA (2012) An immunohistochemical signature comprising PTEN, MYC, and Ki67 predicts progression in prostate cancer patients receiving adjuvant docetaxel after prostatectomy. Cancer 118: 6063-6071.

Ben-Porath I, Thomson MW, Carey VJ, Ge R, Bell GW, Regev A, Weinberg RA (2008) An embryonic stem cell-like gene expression signature in poorly differentiated aggressive human tumors. Nat Genet 40: 499-507.

Berney DM, Gopalan A, Kudahetti S, Fisher G, Ambroisine L, Foster CS, Reuter V, Eastham J, Moller H, Kattan MW, Gerald W, Cooper C, Scardino P, Cuzick J (2009) Ki-67 and outcome in clinically localised prostate cancer: analysis of conservatively treated prostate cancer patients from the Trans-Atlantic Prostate Group study. Br J Cancer 100: 888-893.
Camp RL, Dolled-Filhart M, Rimm DL (2004) X-tile: a new bio-informatics tool for biomarker assessment and outcome-based cut-point optimization. Clin Cancer Res 10: 7252-7259.

Cantile M, Kisslinger A, Cindolo L, Schiavo G, D’Antò V, Franco R, Altieri V, Gallo A, Villacci A, Tramontano D, Cillo C (2005) cAMP induced modifications of HOX D gene expression in prostate cells allow the identification of a chromosomal area involved in vivo with neuroendocrine differentiation of human advanced prostate cancers. J Cell Physiol 205: 202-210.

Columbel M, Eaton CL, Hamdy F, Ricci E, van der Pluijm G, Cecchini M, MegeLechevallier F, Clezardin P, Thalmann G (2012) Increased expression of putative cancer stem cell markers in primary prostate cancer is associated with progression of bone metastases. Prostate 72(7): 713-720.

Cuzick J, Berney DM, Fisher G, Mesher D, Møller H, Reid JE, Perry M, Park J, Younus A, Gutin A, Foster CS, Scardino P, Lanchbury JS, Stone S, Transatlantic Prostate Group (2012) Prognostic value of a cell cycle progression signature for prostate cancer death in a conservatively managed needle biopsy cohort. Br J Cancer 106: 1095-1099.

Cuzick J, Swanson GP, Fisher G, Brothman AR, Berney DM, Reid JE, Mesher D, Speights VO, Stankiewicz E, Foster CS, Møller H, Scardino P, Warren JD, Park J, Younus A, Flake DD, Wagner S, Gutin A, Lanchbury JS, Stone S (2011) Prognostic value of an RNA expression signature derived from cell cycle proliferation genes for recurrence and death from prostate cancer: A retrospective study in two cohorts. Lancet Oncol 12: $245-255$.

Epstein JI, Allsbrook WC, Amin MB, Egevad LL, ISUP Grading Committee (2005) The 2005 International Society of Urological Pathology (ISUP) consensus conference on Gleason grading of prostatic carcinoma. Am J Surg Pathol 29: 1228-1242.

Fisher G, Yang ZH, Kudahetti S, Møller H, Scardino P, Cuzick J, Berney DM, Transatlantic Prostate Group (2013) Prognostic value of Ki-67 for prostate cancer death in a conservatively managed cohort. Br J Cancer 108: 271-277.

Khor L-Y, Bae K, Paulus R, Al-Saleem T, Hammond ME, Grignon DJ, Che M, Venkatesan V, Byhardt RW, Rotman M, Hanks GE, Sandler HM, Pollack A (2009) MDM2 and Ki-67 predict for distant metastasis and mortality in men treated with radiotherapy and androgen deprivation for prostate cancer: RTOG 92-02. J Clin Oncol 27: 3177-3184.

Klein EA, Cooperberg MR, Magi-Galluzzi C, Simko JP, Falzarano SM, Maddala T, Chan JM, Li J, Cowan JE, Tsiatis AC, Cherbavaz DB, Pelham RJ, Tenggara-Hunter I, Baehner FL, Knezevic D, Febbo PG, Shak S, Kattan MW, Lee M, Carroll PR (2014) A 17-gene assay to predict prostate cancer aggressiveness in the context of Gleason grade heterogeneity, tumor multifocality, and biopsy undersampling. Eur Urol 66: $550-560$.

Knezevic D, Goddard AD, Natraj N, Cherbavaz DB, Clark-Langone KM, Snable J, Watson D, Falzarano SM, Magi-Galluzzi C, Klein EA, Quale C (2013) Analytical validation of the Oncotype DX prostate cancer assay-a clinical RT-PCR assay optimized for prostate needle biopsies. BMC Genomics 14: 690.

Lee SY, Jeon HM, Kim CH, Ju MK, Bae HS, Park HG, Lim S-C, Han SI, Kang HS (2011) Homeobox gene Dlx-2 is implicated in metabolic stress-induced necrosis. Mol Cancer 10: 113.

Little R (1986) A test of missing completely at random for multivariate data with missing values. J Am Stat Assoc 83: 1198-1202.

Loeb S, Bruinsma SM, Nicholson J, Briganti A, Pickles T, Kakehi Y, Carlsson SV, Roobol MJ (2014) Active surveillance for prostate cancer: a systematic review of clinicopathologic variables and biomarkers for risk stratification. Eur Urol 67: 619-626.

Massagué J (2008) TGF $\beta$ in cancer. Cell 134: 215-230.

McCarty KS, Miller LS, Cox EB, Konrath J, McCarty KS (1985) Estrogen receptor analyses. Correlation of biochemical and immunohistochemical methods using monoclonal antireceptor antibodies. Arch Pathol Lab Med 109: 716-721.

McShane LM, Altman DG, Sauerbrei W, Taube SE, Gion M, Clark GM, Statistics Subcommittee of NCI-EORTC Working Group on Cancer Diagnostics (2006) REporting recommendations for tumor MARKer prognostic studies (REMARK). Breast Cancer Res Treat 100: 229-235.

Morini M, Astigiano S, Gitton Y, Emionite L, Mirisola V, Levi G, Barbieri O (2010) Mutually exclusive expression of DLX2 and DLX5/6 is associated with the metastatic potential of the human breast cancer cell line MDAMB-231. BMC Cancer 10: 649. 
Nagalla S, Chou JW, Willingham MC, Ruiz J, Vaughn JP, Dubey P, Lash TL, Hamilton-Dutoit SJ, Bergh J, Sotiriou C, Black MA, Miller LD (2013) Interactions between immunity, proliferation and molecular subtype in breast cancer prognosis. Genome Biol 14: R34.

Parekh DJ, Ankerst DP, Higgins BA, Hernandez J, Canby-Hagino E, Brand T, Troyer DA, Leach RJ, Thompson IM (2006) External validation of the Prostate Cancer Prevention Trial risk calculator in a screened population. Urology 68: 1152-1155.

Pollack A, DeSilvio M, Khor L-Y, Li R, Al-Saleem TI, Hammond ME, Venkatesan V, Lawton CA, Roach M, Shipley WU, Hanks GE, Sandler HM (2004) Ki-67 staining is a strong predictor of distant metastasis and mortality for men with prostate cancer treated with radiotherapy plus androgen deprivation: Radiation Therapy Oncology Group Trial 92-02. J. Clin Oncol Off J Am Soc Clin Oncol 22: 2133-2140.

Powe DG, Dhondalay GKR, Lemetre C, Allen T, Habashy HO, Ellis IO, Rees R, Ball GR (2014) DACH1: its role as a classifier of long term good prognosis in luminal breast cancer. PloS One 9: e84428.

Ramsay AK, McCracken SRC, Soofi M, Fleming J, Yu AX, Ahmad I, Morland R, Machesky L, Nixon C, Edwards DR, Nuttall RK, Seywright M, Marquez R, Keller E, Leung HY (2011) ERK5 signalling in prostate cancer promotes an invasive phenotype. Br J Cancer 104: 664-672.

Tang P, Huang H, Chang J, Zhao G-F, Lu M-L, Wang Y (2013) Increased expression of DLX2 correlates with advanced stage of gastric adenocarcinoma. World J Gastroenterol 19: 2697-2703.

Verhoven B, Yan Y, Ritter M, Khor L-Y, Hammond E, Jones C, Amin M, Bahary J-P, Zeitzer K, Pollack A (2013) Ki-67 is an independent predictor of metastasis and cause-specific mortality for prostate cancer patients treated on Radiation Therapy Oncology Group (RTOG) 94-08. Int J Radiat Oncol Biol Phys 86: 317-323.

Wang S-Y, Cowan JE, Cary KC, Chan JM, Carroll PR, Cooperberg MR (2013) Limited ability of existing nomograms to predict outcomes in men undergoing active surveillance for prostate cancer. BJU Int 114: E18-E24.

Wang Y, Xia X-Q, Jia Z, Sawyers A, Yao H, Wang-Rodriquez J, Mercola D, McClelland M (2010) In silico estimates of tissue components in surgical samples based on expression profiling data. Cancer Res 70: 6448-6455.

Yilmaz M, Maass D, Tiwari N, Waldmeier L, Schmidt P, Lehembre F, Christofori G (2011) Transcription factor Dlx2 protects from TGF $\beta$ induced cell-cycle arrest and apoptosis. EMBO J 30: 4489-4499.

Zellweger T, Günther S, Zlobec I, Savic S, Sauter G, Moch H, Mattarelli G, Eichenberger T, Curschellas E, Rüfenacht H, Bachmann A, Gasser TC, Mihatsch MJ, Bubendorf L (2009) Tumour growth fraction measured by immunohistochemical staining of Ki67 is an independent prognostic factor in preoperative prostate biopsies with small-volume or low-grade prostate cancer. Int J Cancer 124: 2116-2123.

This work is published under the standard license to publish agreement. After 12 months the work will become freely available and the license terms will switch to a Creative Commons AttributionNonCommercial-Share Alike 4.0 Unported License. 